\title{
Semantic Capital: Its Nature, Value, and Curation
}

\section{Luciano Floridi ${ }^{1,2}$}

Published online: 29 November 2018

(C) Springer Nature B.V. 2018

\section{Introduction: Semantic Capital as Non-economic Capital}

Allow me to be trivial and vague to begin with. There is a wealth of resourcesincluding ideas, insights, discoveries, inventions, traditions, cultures, languages, arts, religions, sciences, narratives, stories, poems, customs and norms, music and songs, games and personal experiences, and advertisements - that we produce, curate, consume, transmit, and inherit as humans. We use this wealth-which I shall define more precisely as semantic capital in the next section - in order to give meaning to, and make sense of, our own existence and the world surrounding us, to define who we are, and to develop an individual and social life. Given its crucial importance, one would expect the concept of semantic capital and its related phenomena to be well-known and extensively theorised. Much to my surprise, this is not the case. In this section, I shall offer an explanation of why there is such a gap. I will return to the definition of what semantic capital is in the next.

In his influential essay "The Forms of Capital", Pierre Bourdieu identifies three categories of capital ((Bourdieu 1986), see also (Bourdieu 2010)): economic, social and cultural. Even without endorsing his analysis, one may agree that there is a significant difference between the three.

Economic capital is what we usually mean by capital tout court, if we add no qualifications, in order to refer to any resource that can enhance one's power to perform economically useful work. In this sense, economic capital is understood as one of the inputs in the production function, like labour. Money is a good example.

Social capital refers to the network of interpersonal relationships (shared sense of identity, shared norms and expectations, mutual acquaintance and recognition, etc.) that can have an economic value, for example in the advancement of one's own personal career, or in the production of public goods for a common good. One reason to attend a prestigious university is also because your classmates may end up as Prime Ministers (Theresa May, David Cameron, Tony Blair, and Margaret Thatcher were all Oxford undergraduates).

Luciano Floridi

luciano.floridi@oii.ox.ac.uk

1 Oxford Internet Institute, University of Oxford, 1 St Giles, Oxford OX1 3JS, UK

2 The Alan Turing Institute, 96 Euston Road, London NW1 2DB, UK 
Finally, cultural capital refers to a person's educational and intellectual resources (especially knowledge and skills) that help to achieve or maintain a higher social status in society.

All three kinds of capital are easier to grasp by providing examples than to define in terms of necessary and sufficient conditions. The terms can seem as vague to us as "semantic capital". The literature on their exact nature, dynamics, and interdependencies is constantly growing, not least because they invite further refinements in terms of human capital, symbolic capital, political capital, intellectual capital, and so forth. So, you may understand my surprise when I began researching the concept of semantic capital and realised that nobody had theorised it, or even formulated it as a term. Before doing any analytic work, let me show you some evidence.

Figures 1 and 2 illustrate the number of hits that Google search returned in July and October 2018, when I searched for "semantic capital". Basically nothing. The increase in the number of returns in October might be due to some public lectures I gave on the topic in between.

Still, on October 14, Google Scholar returned only 80 results, belonging mostly to linguistics (semantic capital as richness in the meaning of a word or expression). When

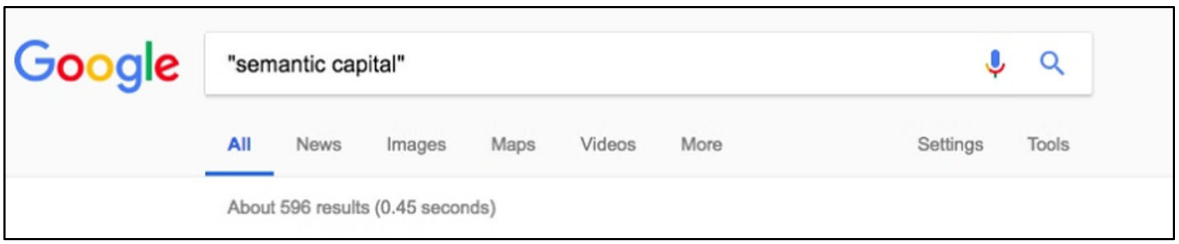

Fig. 1 Occurrences of "semantic capital" in a Google search, 5 July 2018

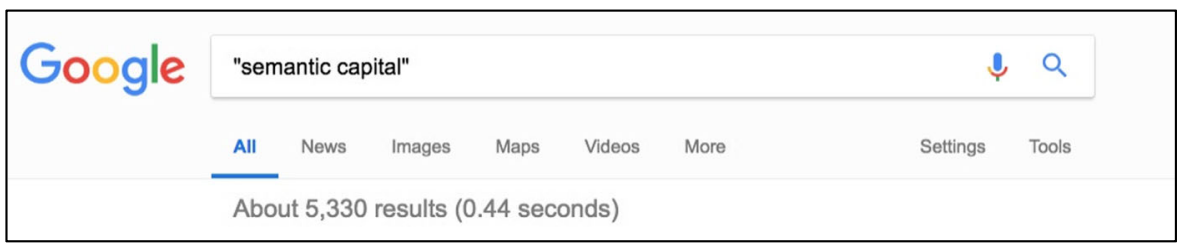

Fig. 2 Occurrences of "semantic capital" in a Google search, 14 October 2018

I checked Wikipedia, the result was even starker: the whole database of the English version contains no occurrence of "semantic capital" anywhere, see Fig. 3.

Why such a lack of interest in a concept that seems to be so significant? As I shall indicate in the next section, it is not because the concept cannot be defined clearly and precisely. It

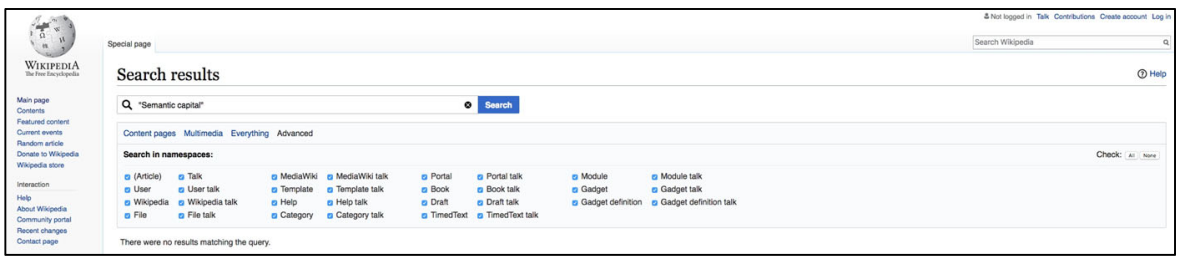

Fig. 3 Occurrences of "semantic capital" in the whole database of English Wikipedia, 14 October 2018 
can. Nor is it because "semantic capital" is not that important. I shall show that it actually is. The explanation may be a different one. All the concepts of "capital" that I have listed above, whether Bourdieu's or not, have a strong family resemblance: they belong to the economic domain of production, distribution and consumption of valuable goods, services or social positions. This means that, in each case, the philosophically heavy-lifting work is done by the noun, "capital", not by the adjective qualifying it, exactly the opposite of what happens with "semantic capital", where I shall argue that the whole emphasis is on "semantic". Consider Bourdieu's approach, which is paradigmatic. As he writes:

The different types of capital [social and cultural, my note] can be derived from economic capital, but only at the cost of a more or less great effort of transformation, which is needed to produce the type of power effective in the field in question. (p. 24)

This "economic transformability" has confined the debate about forms of capital to those that may not yet be economic, but presuppose economic capital as a foundational concept in terms of which they are all inter-translatable, as the least common denominator, and must be understood, as either having, or being able to acquire, some value that may be monetisable. In other words, capital tout court (the economic kind) is the criterion used to qualify and measure all these other forms of capital in terms of $\$ \$ \$$. If something does not fit the economic metrics, it simply fails to be included. And if anything almost fits it, like cultural capital, then it gets reduced to the economic kind, which dominates the discourse as the only systemic attractor. Thus, human capital, to use another example, refers to all those embodied human talents, skills, knowledge etc. resulting in the ability to perform labour so as to produce economic value. This economic reductionism does not need to be Marxian but converges with Marx's analysis of the primacy of the economic moment over the cultural one. In the end, the whole debate on not-yet-economic forms of capital is dominated by a philosophy of economics as first philosophy, a tunnel vision that has so far missed what I would argue is really the most important form of capital, the one that far surpasses in value (understood in terms of what we care about, not merely of what we are ready to pay for) any economic capital, and hence any other kind of capital translatable into it. I am talking about our semantic capital. At this point, the concept may no longer be trivial, but it is still vague. So, the time has come to provide a definition of it and fill the gap.

\section{A Definition of Semantic Capital}

Having failed to identify a pre-existent definition of semantic capital, the only alternative left is to offer one. Here is my proposal:

(SC) Semantic Capital $=_{\text {def. }}$ any content that can enhance someone's power to give meaning to and make sense of (semanticise) something.

Almost every word in (SC) needs to be unpacked. Let us see how.

The "content" in the definition refers to well-formed and meaningful data (Floridi 2010a). The data are some absences of uniformity: for example, a sound in the silence, 
a light in the darkness, a black dot on a white page, already count as data. One may say that there are always data, because total and absolute uniformity is as rare in the universe as complete randomness is. Furthermore, data come together, and such clusters then constitute the game you played when you were a child; the sound of a bell in the village in which you spend your holidays; a song, so intimately mixed with a significant experience, which you keep hearing again in so many difference circumstances of your life; the inevitable taste of any Proustian moment ("The taste was that of the little piece of madeleine which [...] my aunt Léonie used to give me", In Search of Lost Time); the movies you have watched, the gossip you shared; the smell of a new car; the first feeling of a new wedding ring around your finger. All these clusters of data need to be structured, not merely (perceived as) gathered together, hence their syntactic well-formedness. And they need to be meaningful. This is not circular, if we take the word "someone" in (SC) in its token - as opposed to type - value, that is, as referring to a person who enjoys a semantic capital that consists in content, some of which already has meaning because she is born within a context where meaningful data pre-date her existence. Like one's own DNA or natural language, some semantic capital is personal but not individual, and it is often the personal not-individual semantic capital that enables one to accumulate the only-individual kind (it is only a shared language that enables one to formulate his own unique sentences).

A beautiful example of this rich and complex interplay between past and present, public and private, personal and individual semantic capital is offered by the words uttered by Dido when she acknowledges her love for Aeneas:

agnosco veteris vestigia flammae

I recognise the traces of the old flame.

Aeneid, Book IV, line 23

Sometimes vestigia is translated as "signs", some other times as "scars". Scars may be more accurate here. Flames leave scars on people, and Dido's love for Aeneas brings back painful memories/scars of a previous love. Yet the important point for us here is not the physical intensity (Dido's passion will make her forget her vow of chastity) but the oldmeaningfulness of such "vestigia". What Dido feels for Aeneas has meaning also because she has meaningfully felt it before for her dead husband Sychaeus. It is not new meaningfulness, but old meaningfulness that acquires more and new meaningfulness. The process is not a mere matter of accumulation, but also a re-interpretation, adaptation, and enrichment. Her love for Sychaeus is also modified backwards by her love for Aeneas. And her personal feeling will be felt again by others. Dante uses the same verses to acknowledge Beatrice's presence while leaving behind Virgil on his journey through Purgatory:

... conosco i segni de l'antica fiamma

I know the signs of the ancient flame

Purgatorio, XXX, 46-48

Yet now he means something slightly different. Because we are not talking of "recognition", but of "cognition": the flame is the same, the meaningfulness of Beatrice in the past is rekindled by the meaningfulness of Beatrice in the present. There is continuity (more wood on an existing fire), not mixed with the painful absence 
of a dead loved one. Dante's "signs" are not scars but sparks of an old flame that is reignited by the same person. And so the process continues, and when we read the epigraph of Thomas Hardy's Poems of 1912-13 "veteris vestigia flammae", the verb, which had changed from Virgil's "recognising comparatively" to Dante's "cognising the same again", has disappeared, and the vestigia are neither scars nor signs, but traces left behind of some past meaningfulness, now getting cold. Each iteration builds on the previous one and yet moves further away from it, in a process of enrichment of that particular semantic capital that is so much part of the importance of history. We all inherit the semantic scars, signs and traces left by others for us, on us. Many such vestigia are made possible by natural languages, the most important conduit of semantic capital. We learn our own mother tongue from a community of speakers, which predates our existence, but we are also part of the community that keeps it alive, transforms it, and transmits it to the next generation, like Dido's flame in Virgil.

How data acquire their meaning for each person is a social and diachronic question, not a logical paradox. Understanding how clusters of data acquire their meaning in the first place, that is, how humanity, namely the type-someone, has managed to develop the rich semantics it enjoys in the first place, is known as the symbol grounding problem (Taddeo and Floridi 2005, 2007). Luckily it is a problem of which we need to be aware, but that we do not have to try to solve here (for a proposal see (Floridi 2010b, 2019). Because in (SC) we are talking about a someone-token, like Virgil, Dante, Hardy, you, or me.

This is another key element in the definition: persons have semantic capital, animals and robots do not, but most importantly cannot. On the one hand, animals handle only meaning at most, but never sense. They may be told to have cultural capital, but this seems closer to Bourdieu's economic concept. ${ }^{1}$ They do not have narratives within which meanings are embedded: they may feel the flames, but have no reflective sense of the vestigia, their past and future. On the other hand, robots only handle syntax, not even meaning, and syntactical flames can leave no scar, in the same sense in which the simulation of a fire cannot burn. One may object that families, friends, teams, groups, organisations, institutions, political parties and whole nations can all have semantic capital. Of course, but the reply is obvious: this is true only insofar as they are made of past, present, or future persons. Any organisation without the persons constituting it is devoid of both meaning and sense. Semantic capital is not the only thing that defines us, but it is certainly what defines only us.

The next step is to note the absence of "truthful" in "well-formed and meaningful data", that is, content in (SC). I have argued that, if one adds "truthful", then one is actually talking about information (the factual kind, like "Paris is the capital of France", see (Floridi 2010b)), but here a reference to information would be too strict. This is why I suggested "content" instead. Beliefs in Red Riding Hood, Robin Hood, Santa Claus or some astrological beliefs are well-formed and meaningful data that can be part of a person's semantic capital as much as beliefs in Julius Caesar, Napoleon, JFK or some basic notions of astronomy. It may not be the best semantic capital, but this is another question. Here (more on this presently), what matters is not whether some content is true or untrue (or "false", if you endorse a binary theory of truth), but whether that content provides a person holding it with the means to give meaning to something and

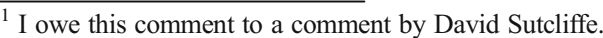


embed that meaningful something into a more general narrative that makes sense to that person. I shall return to this point in section 6 .

The twofold task of "giving meaning" and "making sense" in (SC) is what the neologism "semanticise" seeks to convey in the definition. It is nothing odd, just a short-cut for a familiar experience. Sometimes, we understand what someone said and yet are unable to make any sense of it. I am not talking only about some metaphorical or symbolic interpretations. This is indeed how Macbeth understands the meaning but not the sense of "Macbeth shall never vanquished be, until Great Birnam wood to high Dunsinane hill Shall come against him" (Shakespeare, Macbeth Act 4 Scene 1). I am also talking about the inability to make sense of something the meaning of which we have understood, but cannot square with our own view of the world. A beautiful example is given by Shakespeare in Romeo and Juliet (Act 3 Scene 5). When Capulet asks Juliet whether she is proud of the marriage he has arranged for her, her reply is that:

Not proud, you have; but thankful, that you have:

Proud can I never be of what I hate;

But thankful even for hate, that is meant love.

Her father grasps the meaning of her words, but cannot (or does not want to) make sense of her reply:

How now, how now, chop-logic! What is this?

'Proud', and 'I thank you', and 'I thank you not';

And yet "not proud" mistress minion, you,

Thank me no thankings, nor, proud me no prouds,

$[\ldots]$

For Capulet, the sense of Juliet's reply is broken, because it does not fit his expectations, the circumstances, the logic of his narrative, what should happen, in short his own way of making sense of the world. He gets the meaning of her words but refuses to grasp their overall sense. To him her words are a square peg for a round hole. Semanticisation requires not only meaning but also sense- and when sense breaks down, you have just logic chopping. Juliet's reply makes a lot of sense, it is not choplogic within her (and indeed our) semantic capital, but it is chop-logic for Capulet.

The last point to clarify is "enhance someone's power". Note the similarity with the standard definition of economic capital provided in Section 1. Semantic capital is a resource: the input in a productive function. The output is what we often call "reality". It is how I understand the concept of Lebenswelt ("lifeworld"), the meaningful and "senseful" world that we take for granted as authentic, the one that is revealed only when we bump against the meaningless or the senseless. The main difference is that the work done is mental and existential. It is not economic but underpins all the other economic ones. Of course, Alice may be better off if she has a rich semantic capital (imagine she is able to speak many natural languages) but this is irrelevant. The value of Alice's semantic capital (her natural languages included) consists in the power it gives to Alice to make her life, her world, her identity, her behaviour and experience significant ("it means something") and intelligible ("it has some sense"). Alice designs her reality through her semantic capital, and her meaningful and "senseful" reality 
further enriches her semantic capital. This virtuous circle may seem almost a tautology, as if one were to say, pompously, that "meaning meaning-fies and sense sens-ifies". But all I am saying is simply that fires feed fire. Semantic capital generates semantic capital. Or if you prefer a mathematical analogy, semantic capital is the fixed (or invariant) point of the productive function, in the same way in which $a$ is a fixed point of the function $f(x)$ if $f(a)=a$. When semantic capital works unproblematically this is because semanticisation maps semantic capital to itself. No chop-logic but only a growth in meaning and sense.

\section{The Ultimate Value of Semantic Capital}

Our identities, lives, experiences, interactions and conceptualisations of the world we inhabit and share would be pointless and empty (i.e. lacking any meaning or sense), if our semantic capital did not fill them with value. Minds cannot bear the meaningless and the senseless, and they fill this vacuum with any semantic capital they may have or create, be it magic stories, mythological Greek gods, pop stars and their songs, the most recent blog we read, our love for someone, or hate for someone else. Semantic capital enhances our power to perform existentially useful work, to paraphrase the definition of economic capital. This is why it is the most precious capital we have. Without it, there is only emptiness and bareness, there can be no personal identity or social relations, let alone economic interchanges. Semantic capital is the top soil of our lives: it is the ultimate transcendental condition, because it makes possible the other forms of mental life, including the social, political and economic ones, not just because a meaningless and senseless life is not worth living, but because it is simply not liveable, as Juliet and Romeo remind us. Their story is (also) the unfolding of a tragic semantic bankruptcy. ${ }^{2}$

It follows that semantic capital is so valuable that even life itself may not have more value than it. This is why Dante can excuse Cato, who committed suicide to remain faithful to his semantic capital:

libertà va cercando, ch'è sì cara,

come sa chi per lei vita rifiuta.

he seeks freedom, that is so dear,

as one knows, who gives up his life for it.

Dante, Purgatory, Canto I, vv. 70-72 (my translation).

In interpreting the Delphic maxim "know thyself" ( $\gamma \nu \tilde{\omega} \theta \iota \sigma \varepsilon \alpha v \tau o ́ v)$, Socrates was right: the unexamined life is not worth living. But knowing oneself is also knowing our own semantic capital and being coherently content about it. If we are, our semantic capital may be so precious that we may be readier to sacrifice our lives for it, rather than erode it or corrupt it. A great illustration is provided by a famous epigram, attributed to Simonides, which commemorates the Spartans who died in the Battle of Thermopylae (480 BC) (my transaltion):

\footnotetext{
$\overline{{ }^{2} \text { I owe this comment to Jon Pokroy. }}$
} 


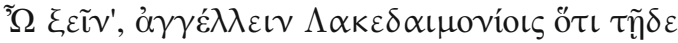

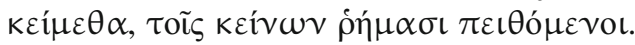

Oh stranger, announce to the Lacedaemonians that we lie here, obedient to their words.

The words that interest us here are two. Occasionally, " $\rho \hat{\eta} \mu \alpha \sigma \iota$ " (words) is replaced in the tradition by the term "vouínoเs", which means "laws" or "orders". It is nice to have such latitude, because this is the semantic capital the Spartans died for: the normative nature of semantics, what ought to be the case, no matter what the cost, is the counterpart of the normative nature of one's behaviour, what must be done, at all

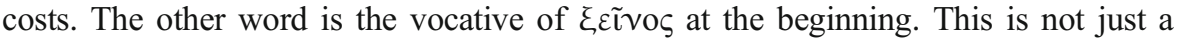
"foreigner or stranger", it is also a "guest", someone who is expected to welcome, and be welcome within, the semantic space represented by the place and the epigram. As a whole, semantic capital cannot be entirely individualistic. We make it our own, but most of it is a personal and social wealth we share, like languages.

\section{The Logic of Semantic Capital}

Semantic capital is better studied from a multidisciplinary perspective, combining cultural studies, hermeneutics, history (of art, of religion, of science...), information and library science, philosophy, semiotics, just to mention some obvious disciplines. Likewise, many writers seem to have had semantic capital at the core of their works: Jorge Luis Borges (The Library of Babel), Italo Calvino (Mr Palomar), Georges Perec (Life: A User's Manual), Robert Pirsig (Zen and the Art of Motorcycle Maintenance), Danilo Kiš (The Encyclopedia of the Dead), in this case just to mention some personal favourites. But what is the logic of semantic capital? Or to be more explicit: if the logic of profit is what shapes the dynamics of economic capital, what is the equivalent mechanism that underlies the functioning and dynamics of semantic capital?

The necessary feature that any semantic capital must preserve is coherence. Without coherence, semanticisation fails, because the same reality semanticised in contradictory ways pulls a person, a group or a society apart. A black cat cannot be interpreted as bringing bad luck and not bringing bad luck at the same time and in the same sense without crashing a whole world view. So, the hallmark of poor or ineffective semanticisation is precisely the presence of inconsistencies or incongruities, lack of cohesiveness, or a patching up that continuously requires increasingly bigger efforts of re-organisation of the whole narrative.

In simple narrative terms, this is typical of soap operas. At some point, everything and its opposite becomes possible and this brings about an "anything goes" reality, which removes any stability and overall, permanent sense. Take Stefano DiMera, the fictional character from the American soap opera Days of Our Lives, (more than 13,460 episodes so far). Named the all-time best villain, ${ }^{3}$ he is the character who has (apparently) died the most times, ${ }^{4}$ by fire, gunshots, explosions, a stroke, brain tumour, and heart attack. The character died only with the death of the actor, Joseph Peter

\footnotetext{
${ }^{3}$ Soap Opera Digest, http://www.soapoperadigest.com/soapstarstats/josephmascolobio/

${ }^{4}$ Fame10, https://www.fame10.com/entertainment/6-soap-opera-characters-who-have-died-the-most-times/
} 
Mascolo, in 2016. But while alive, everything that happened to DiMera was choplogic: inconsistent, reversible, unreliable.

When inconsistencies arise in one's semantic capital, this results in a loss of value, because that part of one's semantic capital can no longer be productive (it is not merely "unproductive") and may actually start devaluing other parts of our semantic capital. Some cauterisation is always possible: that corner of our semanticised world can simply be quarantined, archived, forgotten, put away, like the promise we made to a schoolmate to be BFFs ("best friends forever"); or they are postponed, delayed to an open future, like the plan to learn to play a musical instrument one day. Procrastination is a powerful narrative tool. All these things can be easily removed without necessarily affecting the overall narrative of our lives too badly. Paraconsistency can work in formal logic to limit the damage of what can be inferred from contradictory statements. It certainly has its place in our semantic capital.

It is clear that we are masters in rewriting our existential stories - as we have to be. Unfortunately, the very use and production of semantic capital inevitably generates contradictory tensions: the world changes, other semanticisations are also at work, often competitively (maybe Alice and Bob semanticise their relationship differently), perhaps imposed by other agents (see Juliet and Capulet), and there are always longer and more macroscopic trends (take Brexit and how voters have had to include it within their own semantic capital), so what was semanticised in one way today may need to be re-semanticised in a different way tomorrow.

Sometimes, re-semanticisation involves a straightforward falsification process. King Lear offers a tragic example. He entirely changes his mind about his daughters. In more mundane terms, if Alice and Bob divorce, the process is one of dramatic and painful resemanticisation (just think of what happens to all those wedding photographs in which they were both smiling). To use an epistemological term, it is a Kuhnian revolution (Kuhn 2012) that shifts their fundamental, semantic paradigm.

More often, however, the pressure from the world is less dramatic, and slight adaptations and modifications can help one's semantic capital to keep working. In terms of Lakatos' epistemology (Lakatos 1979), Alice may adopt auxiliary interpretations and re-interpret the difficulties she has encountered rather than changing too dramatically her semanticisation, in order to save the core of her semantic capital. Despite the evidence, she convinces herself that Bob still loves her, that he is not really betraying her, but only having a mid-life crisis of negligible importance. Semantic capital helps in this case too: in a few steps, sexual adultery may be interpreted as a bit less tragic moral betrayal, which then becomes a milder extramarital infidelity, which becomes just a temporary cheating, which becomes a forgivable affair, which ends up being an unfortunate but forgettable and negligible fling. A shipwreck becomes a mere hiccup, which Alice is able to make sense of within her own narrative without having to change it too radically.

Similar forms of editorial curation of our narratives are crucial in the logic of semantic capital. There is no word to summarise all these logical manoeuvres made to ensure that our semantic capital remains coherent and hence works as effectively, efficiently and productively as possible. So, let me adapt a concept and a technical term from Aristotle: anagnorisis ( $\alpha \vee \alpha \gamma \vee \omega ́ \rho \iota \sigma \iota \varsigma)$, often translated as "recognition" or sometimes as "realisation", the word I shall use for reasons that will be clear presently. 
Aristotle introduces the concept of "realisation" in his Poetics to refer to a cognitive turning point in a narrative when characters become aware of the real nature of a situation, especially their own or other characters' real identities. In Aristotle's words (but my translation), it is:

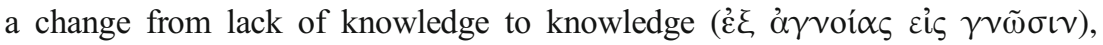
producing love or hate between the persons destined by the poet for good or bad fortune (Aristotle, Poetics, 1452a).

The classic example is Oedipus, who realises much later that he killed his father and married his mother. The crucial point is that true "realisation" is not a process of falsification but of profound re-semanticisation that nevertheless maintains unchanged all the truth values of the narrative, but gives them a completely different interpretation. It may be compared to what in philosophy of science is called "saving the phenomena". It is not the case that Oedipus believed that the man was not his father and the woman

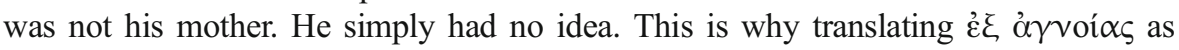
"from ignorance" may be misleading, as if the realisation were a shift from " $S$ believes that $\neg p$ " to " $S$ believes that $p$ ", e.g., from "Oedipus believes this person is not his father" to "Oedipus believes that this person is his father". The shift is rather from " $S \neg$ believes that $p$ " to " $S$ believes that $p$ ".

So here is an adapted definition of anagnorisis as realisation:

(R) Given an information flow, anagnorisis as realisation is the information process (epistemic change) through which a later stage in the information flow (the acquisition of new information) forces a new, non-falsifying, reinterpretation of the whole information flow (all information previously and subsequently received).

The importance of this non-falsificationist concept of "realisation" may be grasped more easily when one understands that the whole Star Wars series must be coherent with the later realisation, in The Empire Strikes Back, that Darth Vader is Anakin Skywalker, the father of Luke Skywalker. Likewise, nothing in the series should contradict, either backwards or forward, the realisation, in Return of the Jedi, that Luke Skywalker and Princess Leia Organa are siblings. They do love each other, but not romantically, as Princess Leia and Han Solo did. Likewise, Macbeth finally realises in what non-falsificationist sense the "Great Birnam wood to high Dunsinane hill Shall come against him". Movies like The Sixth Sense or The Others play a similar narrative trick with the audience as well.

Realisation as re-semanticisation is what enables Alice, now divorced from Bob but happily married to Carol, ${ }^{5}$ to re-interpret her life as a story that was always meant to be fulfilled by her new relationship. She did love Bob but not in the same way as she now loves and is loved by Carol. Different pieces of her life can still fit together as parts of the same narrative. Coherence is preserved. The overall semanticisation is saved.

As in Star Wars, and unlike what happens in Days of Our Lives, in real life realisations are turning points that are irreversible. All the past and the future gets recoloured, interpretatively, in the light of the new narrative. Nothing becomes false, but

\footnotetext{
$\overline{{ }^{5} \text { https://en.wikipedia.org/wiki/Alice_and_Bob }}$
} 
some crucial truths become true in a different way. Minds do not bear any semantic vacuum, so they semanticise; but they cannot endure too many semantic earthquakes either, that is why they continuously "realise". In real life, our realisations are often small adjustments. Dramatic realisations happen rarely. We can only change the deep meanings and senses of our semanticisation a few times, if at all, least we undo the whole tapestry of an acceptable and intelligible existence. The result is that profound realisations may come with a sense of enriched otherness. Alice feels like a different person who does not deny who she was, but builds on that and enjoys her new self. The most successful realisations do not burn past narratives, they write new chapters coherent with them.

In this section, I have argued that the logic of semantic capital is above all the logic of realisation. So far, I have assumed that semantic capital has value and that this value can grow, but I have said nothing about the growth of semantic capital and its forms. This is the topic of the next section.

\section{The Growth of Semantic Capital}

In this section too, I can only sketch some considerations about the (morphology of the) growth of semantic capital, which will deserve a much deeper and more thorough investigation in the future. The conceptual distinctions I wish to import are from the classic analysis of the productivity and appreciation of economic capital. Let me start with a simple example.

A car used for personal transportation is not a capital asset because it is not an input in a production function. Furthermore, it is unproductive and depreciates through time (Fig. 4A). However, the same car, used for peer-to-peer ridesharing, becomes a productive asset, even if its depreciation remains unchanged (Fig. 4B). This gives a different meaning to "uberization", now understood as the process of transforming an unproductive good into a productive capital asset. Imagine next that, after a while, the same car becomes an antique. It may no longer be used as a capital asset (it stops being used for ridesharing), so it is unproductive again but, as a collector's item, its value starts accruing (Fig. 4C). Finally, suppose that the same car, now an antique, is used for wedding ceremonies. This is the best kind of capital: productive and appreciating (Fig. 4D). The same analysis can be adopted for semantic capital, not in the reductive sense, already criticised - namely, that semantic capital is only a mere form of capital tout court - but in the analogical sense that the same distinctions can help us understand better the growth of semantic capital. In this case, let me start with an academic example.

Scholastic knowledge is semantic capital in A: it depreciates quickly - it is soon forgotten - and is unproductive, as it really does not help to semanticise anything. So, strictly speaking, it is not a capital yet, like my own car. Any internal discourse within a discipline that will never leave the pages of unknown specialised journals is a good reminder. Of course, I am not referring to what historians or sociologists of knowledge, for example, will be able to extract from it. The two levels (object-level and meta-level) should not be confused. Scholastic knowledge is for one's own consumption. It can be an act of love (most scholarship and scientific research is really just a tribute to what we admire and cherish), but it should be seen for what it is, a semantic glass bead game, played in Castalia (Hesse 1972). 


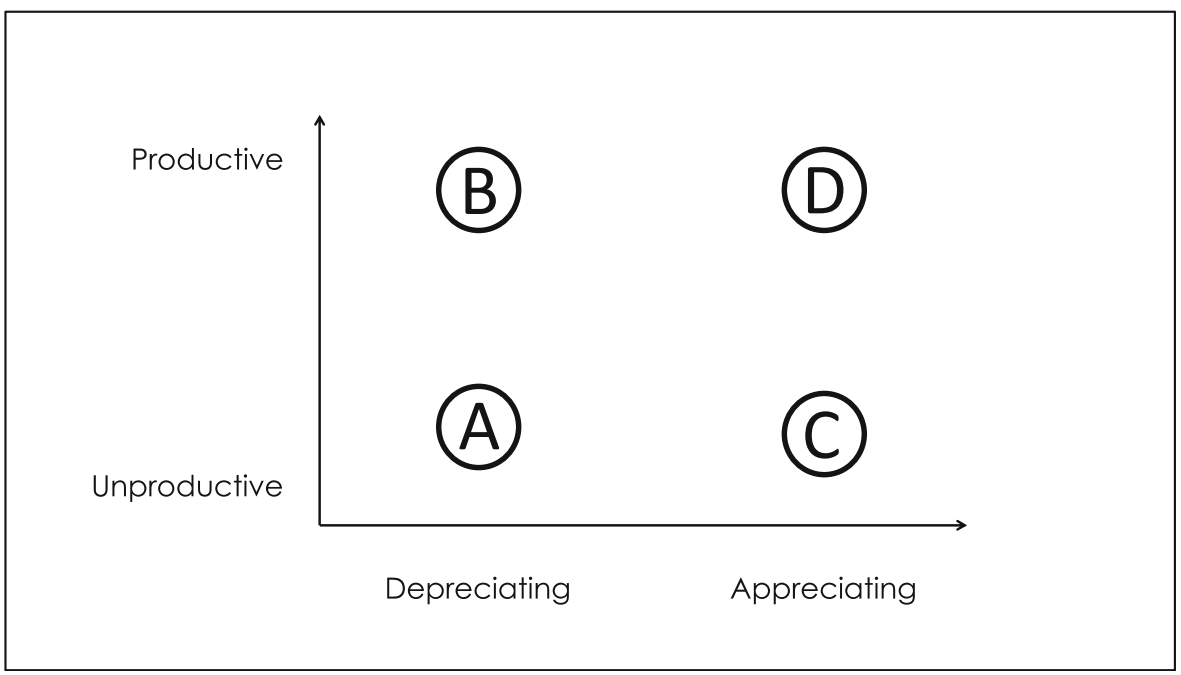

Fig. 4 The nature of semantic capital

Fashionable knowledge is in B. It is the uberization of scholasticism. It still depreciates quickly, but at least it may be productive in terms of semanticisation. In its best form it takes the shape of New York Times best-selling scientific divulgation for the unfathomable "educated public". It is not supposed to be read by somebody in the future, but by everybody in the present. Its authors are driven by literary agents, the real engine behind what makes it into the circle.

One may label knowledge in $\mathrm{C}$ as academic: it is the appreciating kind of semantic capital that is not productive. A lot of good science is of this kind. Whenever we submit a grant, we pretend that academic knowledge has some utilitarian value in a production process that will make a real difference (it is called "impact") in the world, but the truth is that, in many cases, its value is intrinsic, like a collector's car. Only a fool would state that some research is done for its own sake, to know more and better a particular topic. Such a degree of honesty is not rewarded.

Finally, in D, we find authentic knowledge, which is both productive and appreciating. The best science and scholarship is here, and with a bit of luck is recognised by grants, accolades, awards and prizes of many kinds. It is what more likely changes how we semanticise the world and ourselves.

If this mapping is not too crude and more or less acceptable - the four points A, B, C, D should be seen as orientations, not as sets - then a similar taxonomy can be extended to documents that solidify the accrual of semantic capital. Semantic capital in A comprises trash novels, Facebook cats, and Twitter gossip. B is populated by semantic capital in the form of fashion magazines and daily news. The semantic capital in $\mathrm{C}$ can help understand epistemic filter bubbles: available but inaccessible semantic capital occurs here, its value outside the bubble may appreciate, but its productivity within the bubble remains zero. Finally, in D, we find the best of our semantic capital: some art, culture, and science belongs here. Above all, in D we find what we call "classics", the last topic I wish to discuss in this section. 
It is common to describe a literary classic, like the Odyssey, as an open and boundless source of meaning and sense. Italo Calvino phrased this idea impeccably:

a classic is a book which even when we read it for the first time gives the sense of rereading something we have read before [and] a classic is a book which has never exhausted all it has to say to its readers [and] classics are books which, the more we think we know them through hearsay, the more original, unexpected, and innovative we find them when we actually read them (Calvino 1999).

Such semantic richness is indeed what makes a classic classic. But from the perspective adopted in this article, this is not enough, and perhaps not even the most important feature of a classic. Because, as semantic capital, a classic is above all an open and inexhaustible resource to semanticise ourselves and each other, our lives, and the world surrounding us. So Calvino was also right in stressing that:

a classic is the term given to any book which comes to represent the whole universe, a book on a par with ancient talismans. [And] 'Your" classic is a book to which you cannot remain indifferent, and which helps you define yourself in relation or even in opposition to it (Calvino 1999).

In these last quotations, I recognise vestigia of a theory of semantic capital. Classics are semantic capital that helps us produce meaning and sense. Their different availability and accessibility determine how rich or poor our semanticisation will be. A forest may be a reassuring place, where ethics fights unjust laws, if Alice has Pyle's Robin Hood as part of her semantic capital; or a scary place, where darkness hides monsters, if Bob's semantic capital comprises only the Brothers Grimm's Little Red Riding Hood. The world is semanticised also through our classics because we are also our reading lists. And the order matters. Alice's and Bob's worlds are different also because she read Madame Bovary (1856) and then Anna Karenina (1878), whereas he read Anna Karenina first, and then Madame Bovary. And neither Alice's nor Bob's world may be the same as Carol's, who read both novels after she had read about Dido in the Aeneid. Each of them has a slightly different understanding of Juliet's suicide.

If classics are inexhaustible resources of semanticisation then at least two important consequences follow.

First, classics do not need to be books of course, they can also be any other kind of artefact, as long as they work as resources to semanticise reality: some music ("The Girl from Ipanema"), a painting (Vermeer's "Girl with a Pearl Earing”), or a building (a special balcony in town), as well as the harmless paper knife she inherited from her grandfather and used in a school performance when playing Juliet, may all be part of Alice's semanticisation of what it means to be young and in love. We all have our own, more private classics, Alice's paper knife included; we just call "Classics" those that we share with others. The larger the sharing the bigger the $\mathrm{C}$.

Second, the most important classics we can ever encounter are other persons. Put more abstractly, it is the other that represents the greatest resource that can enable the non-other to semanticise itself and anything else (in somewhat Fichtean terms, it is the non-I that poses the I, much as it may seem the other way round). The two poems about 
the Trojan War sung by Demodocus are not comparable to meeting Odysseus himself and hearing him narrating his adventures first hand. Sartre was wrong when he quipped that "hell is other people". The truth is that hell-or nothingness, understood as complete meaninglessness and senselessness - is the death of the other, the irrecoverable loss of the ultimate richness of semantic capital embodied in a person no longer available and hence forever inaccessible. Here Fahrenheit 451 (Bradbury 2013) offers the perfect metaphor: we are walking classics to each other, and any death is a semantic erasure of the worst kind. It is like burning libraries. Similar risks, some unavoidable, are the topic of the next section, but before closing this section let me quote at length a poem by Borges which I take to be a great illustration of the two senses of classics I just introduced:

\section{The Causes}

The sunsets and generations.

The days and none was the first.

The coolness of water in Adam's

throat. Orderly Paradise.

The eye deciphering the dark.

The love of wolves at dawn.

The word. The hexameter. The mirror.

The Tower of Babel and pride.

The moon that Chaldeans gazed at.

The innumerable sands of the Ganges.

Chuang-Tzu and the butterfly that dreams him.

The golden apples on the islands.

The steps in the wandering labyrinth.

Penelope's infinite tapestry.

The Stoics' circular time.

The coin in the dead man's mouth.

The weight of the sword on the scale.

Each drop of water in the clepsydra.

The eagles, the auspicious days, the legions.

Caesar on the morning of Pharsalia.

The shadow of the crosses over the earth.

The chess and algebra of the Persian.

The footprints of long migrations.

The conquest of kingdoms by the sword.

The relentless compass. The open sea.

The clock's echo in memory.

The king beheaded by the ax.

The incalculable dust which was armies.

The nightingale's voice in Denmark.

The calligrapher's meticulous line.

The face of the suicidal one in the mirror.

The gambler's card. Greedy gold.

The shapes of a cloud in the desert. 
Every arabesque in the kaleidoscope.

Each regret and each tear.

All those things were necessary

so that our hands would meet.

\section{The Risks of Semantic Capital}

As before, a definition may help us focus more clearly on the phenomenon under investigation:

(Risk) Semantic capital risk $=_{\text {def. }}$ the potential of loss of part or all of the value of some content that can no longer enhance someone's power to semanticise something.

Semantic capital risk can occur through projects about, or wrong investment in, content that fails to semanticise. Five kinds of risks are then logically possible: the simple (a) loss of semantic capital; the presence of semantic capital that is (b) unproductive; the productive presence of semantic capital that turns out to be (c) underused or (d) misused; and the presence of semantic capital that, although properly used, (e) depreciates through time. Let me outline each of these in some detail.

The loss of semantic capital is a risk run whenever propaganda, fake news, lies, half-truths, "alternative facts", and other kinds of semantic vandalism take place. Trump's presidency is the most recent example of such a loss of semantic capital. Recall that the logic of semantic capital is that of realisation, and realisation requires at least coherence. Now coherence is hardly obtainable in a world of untruths. In this case, protecting semantic capital means defending truth against falsehood.

Unproductiveness and underuse can be treated together, as belonging to the risk of mummification as a preservation of semantic capital that is lifeless and fruitless. A good example is provided by the parable of the talents in the New Testament (Matthew 25: 14-30; Luke 19: 12-27). Of the three servants asked by their master to manage his goods while he travels, two end up showing their earnings and are rewarded, but the third is punished for having merely buried his single talent. He has made nothing with his semantic capital. In this case, protection comes from the conservation-restoration of cultural heritage, for example, and for any other activity that makes semantic capital work profitably.

The fourth kind is misuse. Here a good example is offered by cultural misappropriation, as when people use other cultures' traditions, religions, symbols, languages, or art without respect, understanding, or legitimacy. The best way to manage this risk of loss of semantic capital, to be understood as capital expropriation, is to promote cultural exchange and understanding, and hence careful attention to what other semanticisations really imply and deserve in terms of respect.

Finally, there is the depreciation of semantic capital. Here the solution has long been known: education. Only through education can semantic capital be preserved, curated, enriched, and transmitted from one generation to the next. 


\section{Conclusion: Semantic Capital and Digital Technologies}

In Section 2, I defined semantic capital as any content — understood as well-formed and meaningful data - that can enhance someone's power to semanticise something. Clearly, given its "data-based" nature, the management of semantic capital has always depended on information technologies, from the invention of the alphabet (recording), to Gutenberg (dissemination), to the computer revolution (manipulation). Each stage in our technological development has generated new opportunities and new challenges. Digital technologies are not an exception. They both exacerbate the risks, outlined in the previous section, and offer new forms of availability, accessibility, utilisation, and capitalisation of semantic capital. Just think of the debate on fake news on the one hand, and the consumption of digital photographs on the other. All this may be complicated in detail but rather obvious as a general trend. What may be worth highlighting are rather two factors that will deserve an independent discussion. On the one hand, digital technologies provide an increasing reservoir of smart agency (Artificial Intelligence) that could support us in the fruitful management of our semantic capital. I am not referring just to curation - think of all the bots used to edit Wikipedia entries (Tsvetkova et al. 2017) — but, more importantly, to the possibility of augmenting our abilities to take advantage of the wealth of semantic capital already available, to use it and enrich it more effectively and efficiently, and hence semanticise our lives and realities better. On the other hand, the digital itself is generating new forms of semantic capital that would have been otherwise impossible, in terms of experiences, new cultural forms, scientific progress, games, music, images, fashions, and so forth. Semantic capital is no longer just analog, it is also increasingly digital, and may not be generated solely by human agents. Our digital semantic capital is beginning to make a difference in our semanticising processes as well. Think of what it means today to search for some information, the expectations about the availability of an answer to any question, or the meaning of authenticity when discussing "deepfakes" (Floridi 2018). How the shift from an analog to an increasingly digital semantic capital is going to affect our semanticisation of our own identities, our lives and our realities is still to be understood. It may take a while before this becomes sufficiently macroscopic to be properly assessed. But that this is happening and that it will become a progressively significant phenomenon is indubitable. We should pay much more attention to it.

Acknowledgements I am very grateful to Kia Nobre for her feedback and suggestions on a first draft of this article. Carl Öhman provided helpful comments about Bourdieu; we may not agree, but I learnt a lot from him. Several meetings enabled me to test some of the ideas presented here, and I am really very grateful to the organisers for such valuable opportunities, many thanks to: Anna Sexton and Eirini Goudarouli, for a keynote at the National Archives, to inaugurate the new Annual Digital Lecture Lecture Series (London, 7 June 2018); Massimiliano Bucchi for a Lectio Magistralis at the University of Trento, to inaugurate the new Master in "Comunicazione delle Scienze" (Trento, 26 September, 2018); Donato Ferri, Donato Iacovone, and Veronica Mutti, for a keynote at EY Digital Summit (Capri, 5 October 2018); Amelia Crosse, for an invited talk given at Exeter College Symposium (Oxford, 10 November, 2018); and finally Francesco Agrusti, Gianmarco Bonavolontà, and Massimiliano Fiorucci for an invited talk given at the Conference on Education and Artificial Intelligence (Rome, 15 November, 2018). Finally, an apology to the reader: this article started as a short editor letter of the topic. It clearly gained a life of its own.

\section{References}

Bourdieu, P. (1986). The forms of capital. In J. G. Richardson (Ed.), Handbook of theory and research for the sociology of education. Westport: Greenwood. 
Bourdieu, P. (2010). Distinction: a social critique of the judgement of taste, Routledge classics. London: Routledge (French orig. 1979).

Bradbury, R. (2013). Fahrenheit 451. London: Harper Voyager.

Calvino, I. (1999). Why read the classics? London: Jonathan Cape (originally "Perché leggere i classici" Mondadori, Milan, 1991).

Floridi, L. (2010a). Information - a very short introduction. Oxford: Oxford University Press.

Floridi, L. (2010b). The philosophy of information. Oxford: Oxford University Press.

Floridi, L. (2018). Artificial intelligence, deepfakes and a future of ectypes. Philosophy \& Technology, 31(3), $317-321$.

Floridi, L. (2019). The logic of information. Oxford: Oxford University Press.

Hesse, H. (1972). The glass bead game: (Magister Ludi). Harmondsworth: Penguin.

Kuhn, T. S. (2012). The structure of scientific revolutions (4th ed.). Chicago: University of Chicago Press.

Lakatos, I. (1979). Proofs and refutations: the logic of mathematical discovery. Cambridge: Cambridge University Press.

Taddeo, M., \& Floridi, L. (2005). Solving the symbol grounding problem: a critical review of fifteen years of research. Journal of Experimental \& Theoretical Artificial Intelligence, 17(4), 419-445.

Taddeo, M., \& Floridi, L. (2007). A Praxical solution of the symbol grounding problem. Minds and Machines, 7(4), 369-389.

Tsvetkova, M., García-Gavilanes, R., Floridi, L., \& Yasseri, T. (2017). Even good bots fight: the case of Wikipedia. PLoS One, 12(2), e0171774. 